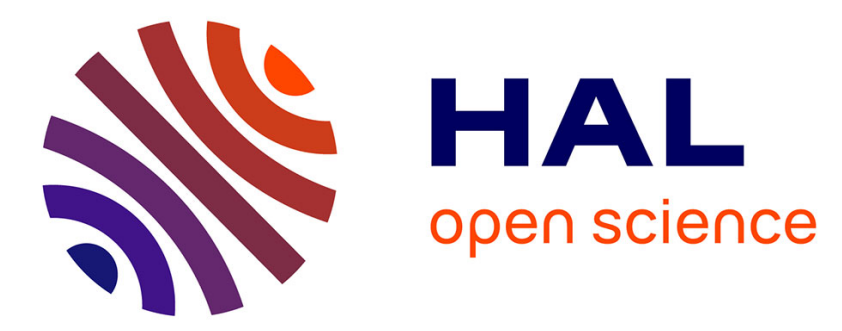

\title{
A new approach for synthesizing plasmonic polymer nanocomposite thin films by combining a gold salt aerosol and an atmospheric pressure low-temperature plasma
}

Elie Nadal, Natalia Milaniak, Hervé Glenat, Gaétan Laroche, Françoise

Massines

\section{To cite this version:}

Elie Nadal, Natalia Milaniak, Hervé Glenat, Gaétan Laroche, Françoise Massines. A new approach for synthesizing plasmonic polymer nanocomposite thin films by combining a gold salt aerosol and an atmospheric pressure low-temperature plasma. Nanotechnology, 2021, 32 (17), pp.175601. 10.1088/1361-6528/abdd60 . hal-03413228

\section{HAL Id: hal-03413228 \\ https://hal.science/hal-03413228}

Submitted on 3 Nov 2021

HAL is a multi-disciplinary open access archive for the deposit and dissemination of scientific research documents, whether they are published or not. The documents may come from teaching and research institutions in France or abroad, or from public or private research centers.
L'archive ouverte pluridisciplinaire HAL, est destinée au dépôt et à la diffusion de documents scientifiques de niveau recherche, publiés ou non, émanant des établissements d'enseignement et de recherche français ou étrangers, des laboratoires publics ou privés. 


\section{A new approach for synthesizing plasmonic polymer nanocomposites thin}

\section{film by combining a gold salt aerosol and an atmospheric pressure DBD.}

Elie Nadal ${ }^{1,2}$, Natalia Milania ${ }^{1,3}$, Hervé Glenat $^{1}$, Gaétan Laroche $^{3}$, Françoise Massines $^{1 *}$

${ }^{1}$ CNRS PROMES, Processes Materials Solar Energy laboratory, Rambla de la Thermodynamique, 66100 Perpignan, France

${ }^{2}$ University of Perpignan Via Domitia, UPVD, 52 Avenue Paul Alduy, 66100, Perpignan, France

${ }^{3}$ Laboratoire d'Ingénierie de Surface, Centre de Recherche sur les Matériaux Avances, Département de génie des mines, de la métallurgie et des matériaux, Université Laval, 1045, Avenue de la Médicine, Québec G1V 0A6, Québec, Canada

Centre de recherche du CHU de Québec, Hôpital St François d'Assise, 10, Rue de L'Espinay, Québec G1L 3L5, Québec, Canada

*francoise.massines@univ-perp.fr

\section{ABSTRACT}

The proof of the concept of a new, one step and safe by design process to synthetize metalpolymer nanocomposites thin films on a large surface is presented. It is based on the injection of an aerosol of a solution of metal (gold) salts dissolved in a polymerisable solvent (isopropanol) into an argon atmospheric pressure dielectric barrier discharge (DBD). The main novelty of this method resides in the fact that the nanoparticles are formed in situ, inside the plasma reactor, in the gas phase. Consequently, the nanoparticle synthesis and deposition is concomitant with the solvent polymerization used to produce the matrix, which makes it 
possible to obtain homogeneous layers of non-agglomerated nanoparticles (NPs) with high NPs density. By toggling between low and high frequency discharges, gold/polymer nanocomposites with different morphologies and optical properties are synthesized. The effect of the concentration of gold in the aerosol and the gas residence time in the plasma as well as the ratio of high and low frequency discharge and their repetition rate are presented. The thin films are systematically characterized by AFM and UV-Visible spectroscopy to analyze their morphologies along with their plasmonic resonances.

Keywords: low temperature plasma, plasmonic nanocomposites, metal salts, aerosols, gold, nanoparticle, atmospheric pressure plasma, dielectric barrier discharge

Abbreviations: Dielectric Barrier Discharge (DBD), isopropanol (IP), nanocomposite (NC) nanoparticles (NPs) 


\section{INTRODUCTION}

Plasmonic nanostructures have proved their potential in the past decades due to their unique properties, which can be used in numerous fields such as biomedicine [1], medical imaging $[2,3]$, biotechnology [4] as well as photovoltaics [5-8]. Theses nanoparticles (NPs), mainly gold and silver NPs, can be found in liquid phase, in the form of colloids or embedded in solid (including polymeric) matrices, often in the form of thin films. In the first case, the ability to precisely control the nanostructures size and shape by using a great diversity of wet synthesis approaches was demonstrated [9] [10]. For the embedded nanoparticles, often referred as nanocomposites (NC), the different methods to produce thin films can be classified in three main synthesis schemes.

The first one is based on the simultaneous or alternate deposition of metallic and matrix material by the usual physical methods such as sputtering, PVD or PECVD [11-13] that can be combined or not with electron lithography or ion beam lithography but also more specific methods such as nanospheres lithography or nanoimprint lithography [14-17]. The potential of these approaches is well known. They enable a very precise control of the nanocomposite morphologies, as for example for producing periodical arrays of nanostructures $[18,19]$.

The second synthesis scheme consists in the incorporation of already synthesised NPs (usual by using wet chemistry synthesis) in a matrix, often a soluble polymer, by mixing the later in the liquid phase [20,21]. This involves complex manipulations of the NPs, and their surface functionalization to avoid NPs aggregation in the mixture [22-24]. This approach also increases the risk of exposure to air and therefore, to oxidation. This method is interesting because it directly benefits from the excellent control that is possible to achieve on the synthesis of the nanoparticles themselves. However, at the end, it turns that the drawbacks of the incorporation technique limit the quality and the control level of the nanocomposite [25].

Lastly, the third approach is based on the in situ synthesis of the NPs directly inside the thin film matrix [26][27,28][29]. In this case, metal salts are mixed with a soluble polymer in the 
liquid phase before thin film deposition. A post-treatment is then performed by heat or radiation to reduce the incorporated metal salts (metal ions) for in situ formation of the metal NPs in the layer. This last approach is very easy to implement and allows for the fabrication of nanocomposites with very high NP concentration, but does not always enable a fine control of the morphology or of the structure of the prepared nanocomposites[30].

All in all, only the second and the third approaches, in which the nanocomposites mixtures are present in the liquid phase, are compatible with low cost methods such as spray, spin-coating, dip-coating and printing [31], often used for the deposition of thin films on large surface areas [32].

This study investigates a new, one-step process of NC thin film coating compatible with the treatment of large surfaces that is inspired by both the atmospheric pressure plasma enhanced chemical vapor polymerization (AP PECVD) and the in situ synthesis approaches. The aim is to use the ability of plasma ionized species to reduce a metallic salt and the energetic species to polymerize a solvent to produce thin films by AP PECVD.

The aim is to control as much as possible the NPs and the NC morphology as well as to improve safety, to reduce the preparation time and cost and to minimize the probability of oxidation of NPs in NCs.

Previous work demonstrated the possibility of synthesizing NPs from metallic salt in plasma. More specifically, thermal plasmas [33], post-discharge of microplasmas [34] and electric discharge in saline solutions [35] were investigated. These studies show the capability of plasma to reduce the molecules of metal in order to create nanoparticles. However, the formation of NPs from metal salts injected directly into a cold plasma at atmospheric pressure (AP) for further deposition on a substrate has never been reported. The route previously explored in AP cold plasma to make $\mathrm{NC}$ thin films, consists in injecting an aerosol containing previously synthesized NPs dispersed in a solvent into a plasma to induce the polymerization process [3639]. These works show the value of modulating the plasma frequency to homogenize the thin 
film [40] and to polymerize a matrix layer in which the nanoparticles are deposited in a simultaneous manner. In addition, these works have also shown that the density of NPs in the $\mathrm{NC}$ can be controlled via the polymerization rate of the solvent or via the modulation of plasmas of different frequencies. At frequencies of typically $1 \mathrm{kHz}$ or lower, the power of the plasma is too low to efficiently polymerize the solvent, but the oscillation of the voltage is slow enough to induce the drift of the NPs towards the surface. At higher frequencies, the increase of the DBD power induces the increase of the polymerization rate of the solvent [41]. Thus, alternating between low frequency and higher frequency plasmas has, for instance, made it possible to control the morphology of both $\mathrm{TiO}_{2} /$ polymer, $\mathrm{TiO}_{2} /$ silica and $\mathrm{SiO}_{2}$ polymer $\mathrm{NC}$ films $[38,39,42,43]$. Despite interesting results, this approach has some limitations, in particular because of the propensity of NPs to aggregate within the aerosol droplet to form agglomerates even before interacting with the plasma [39]. Thus, nucleating NPs in flight in a plasma is an avenue to be explored to avoid aggregation while retaining the possibility of manipulating NPs with plasma frequencies which is one of the objectives of this work.

The plasma source is a plane/plane dielectric barrier discharge (DBD) useful for on-line treatment of large surface [44] and able to alternate low and high frequency discharges $[39,42]$. The originality of the approach is therefore to combine metal salts and this multi-frequency DBD to produce functional NCs with controlled properties in a single step and possibly on large surfaces. Gold salt was chosen as a model because of its resilience to oxidation and because of the large literature allowing to easily relate the plasmonic optical response of the thin film to the NC morphology [45-48].

In order to form gold nanoparticles, the gold ions injected in the aerosols, which are at oxidation degree $3\left(\mathrm{Au}^{\mathrm{III}+}\right)$, need to be reduced. If we consider the usual scheme encountered in wet chemistry approaches, the gold ions are solvated and reduced by an added reducing agent, which leads to the nucleation and further growth of the nanostructures $[9,49-51]$. 
To date, there are, however, no study in the literature that has proposed reaction pathway for this kind of reduction for a metal salt droplet placed inside an atmospheric pressure plasma. A first question that arises is the nature of the salt/solvent mixture when it enters the plasma. More precisely, the state of the droplets injected, that can be partially or fully evaporated leading to respectively either a small drop of salt solution or rather a solid nanocrystal. Considering this fact, several mechanisms could be envisioned: i) direct reduction of the $\mathrm{Au}^{\mathrm{III}+}$ by the electron gas in the plasma, ii) an indirect reaction involving the isopropanol or iii) a direct reduction induced by the high energy state molecules (metastables) present in the plasma and that are known to initiate the chemistry. These fundamental questions are interesting and should be deepened but this is not the purpose of this investigative work, which is rather focused on exploring the potential of the approach, combining metals salt aerosols and a non-equilibrium plasma to produce various NC thin films. The plasma is considered as a "reducing agent" of low or high power depending on its frequency. The reactivity of the gold salt inside the plasma is not known. It depends on the plasma power and the time of interaction of the salt with the plasma. Thus, the study is focused on the effect of the ratio of high and low frequency discharge and their repetition rate, the gas residence time in the plasma and the salt concentration on the aerosol. Thin films are characterized by AFM and UV-visible absorption spectroscopy, the latter giving access to the plasmonic resonance of the system which is directly depended on the NPs morphology and organization within the film.

\section{EXPERIMENTAL SECTION}

Figure 1 is a schematic presentation of the experimental set-up. Solutions of gold salt $\left(\mathrm{HAuCl}_{4} \cdot 3 \mathrm{H}_{2} \mathrm{O}, 99.99 \%\right.$ pure, Aldrich) in reagent grade isopropanol (IP) at $0.015,0.025$ and 0.050 weight percent ( $\%$ of gold mass in the mixture) are first prepared. The solution is then injected in the plasma as an aerosol generated using an atomizer, as described by Fanelli et al 
[41]. Deposition is performed during $20 \mathrm{~min}$ on a circular glass substrate (diameter of $22 \mathrm{~mm}$, thickness of $0.2 \mathrm{~mm}$ ) placed on the lower electrode.

The total flow of Ar gas is $31 . \mathrm{min}^{-1}\left(11 . \mathrm{min}^{-1}\right.$ used in the atomizer to generate the aerosol and 2 1. $\mathrm{min}^{-1}$ for the dilution). The concentration of the gold salt/IP suspension in total Ar flow is $350 \mathrm{ppm}$.

The plasma reactor is composed of two parallel electrodes both of $2 \times 5 \mathrm{~cm}^{2}$ covered by a 1 $\mathrm{mm}$ thick dielectric layer. The aerosol is injected into the $2 \mathrm{~mm}$ gap between the two dielectrics. Once injected, the gas is guided by two zinc selenide bars until its aspiration on the opposite side to avoid lateral precursor losses and a laminar gas flow of constant velocity in the plasma. The pressure is 760 Torr and the mean gas residence time in the plasma zone is $44 \mathrm{~ms}$.

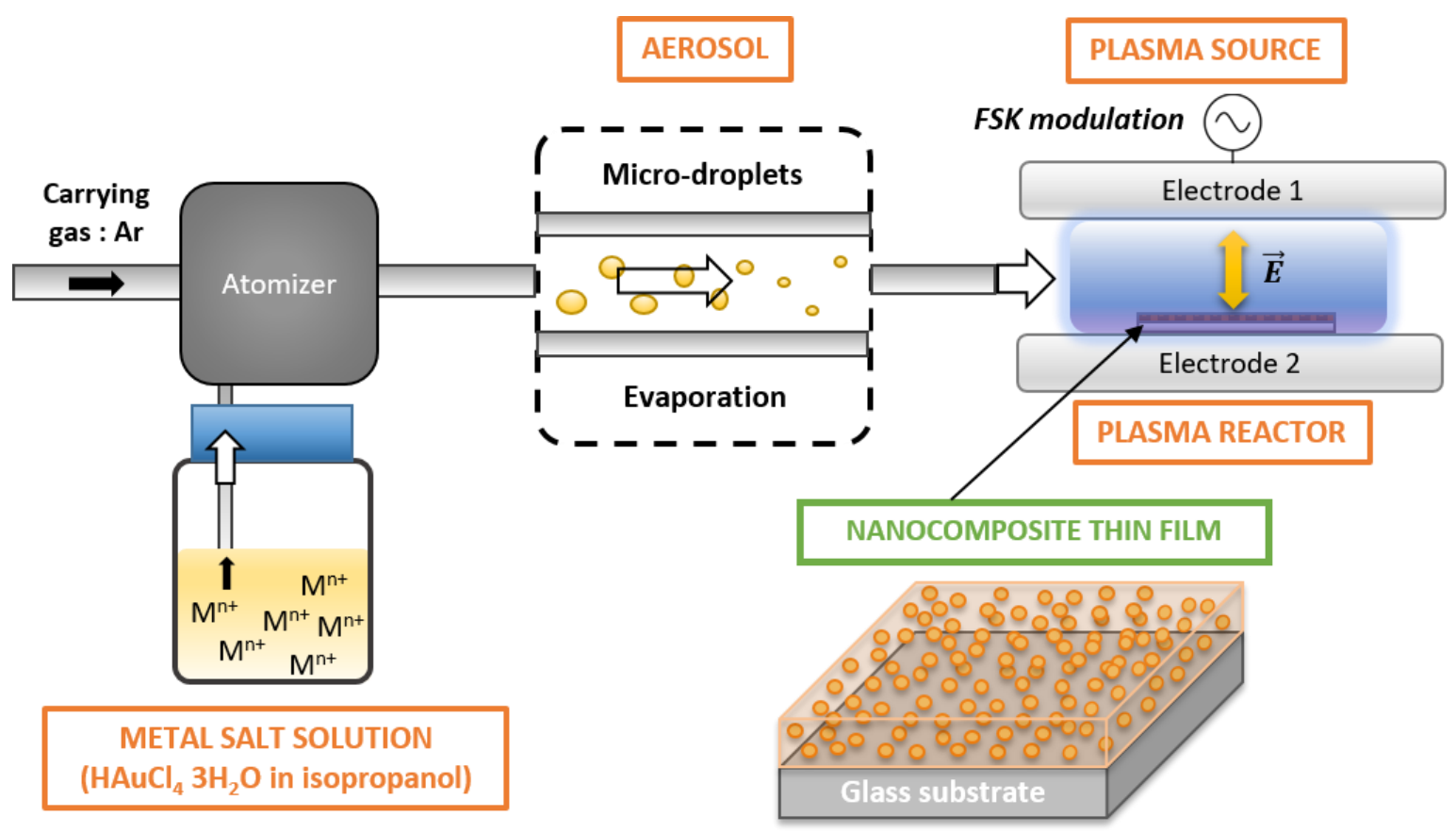

Figure 1: Global view of the nanocomposite synthesis procedure: a metal salt solution is atomized in an Ar flow and the resultant aerosol is injected inside the plasma chamber. The nanoparticles formation, concomitant with the solvent polymerization happens in situ. The use of FSK (alternating $800 \mathrm{~Hz}$ and $20 \mathrm{kHz}$ discharge voltage) leads to the deposition of a nanocomposite film. 
The high voltage is issued from a low frequency signal generator (Agilent 33220) using Frequency Shift Keying (FSK) double modulation and an audio amplifier (Crest CC4000) connected to an up-voltage transformer (Boige et Vignal) and to the top electrode, whilst the bottom electrode is grounded $[38,39]$.

Figure 2 presents one cycle of a typical FSK high voltage waveform applied to the electrodes. FSK is a method for transmitting digital signals. The two binary states, logic 0 (low) and 1 (high), are each represented by an analog waveform. Logic 0 is represented by a wave at a specific frequency and logic 1 is represented by a wave at a different frequency. The FSK waveform is defined by several parameters: the FSK frequency $\left(f_{F S K}=1 / T_{F S K}\right)$, with $\mathrm{T}_{\mathrm{FSK}}$ being the period of the binary signal, the frequency associated with the logic state $1\left(f_{H}=\right.$ $\left.1 / T_{H}\right)$ called high frequency, the frequency associated to the logic state $0\left(f_{L}=1 / T_{L}\right)$ called the low frequency. It is also useful to introduce the NP creation time, $T_{C}$, which correspond to the period during which the $f_{H}$ is applied, and the NP deposition time, $T_{D}$, which corresponds to the period during which the $f_{L}$ is applied. Finally, the duty cycle $(D C)$ is defined as $T_{C} / T_{F S K}$ : the higher is the DC, the longer is $f_{H}$ applied.

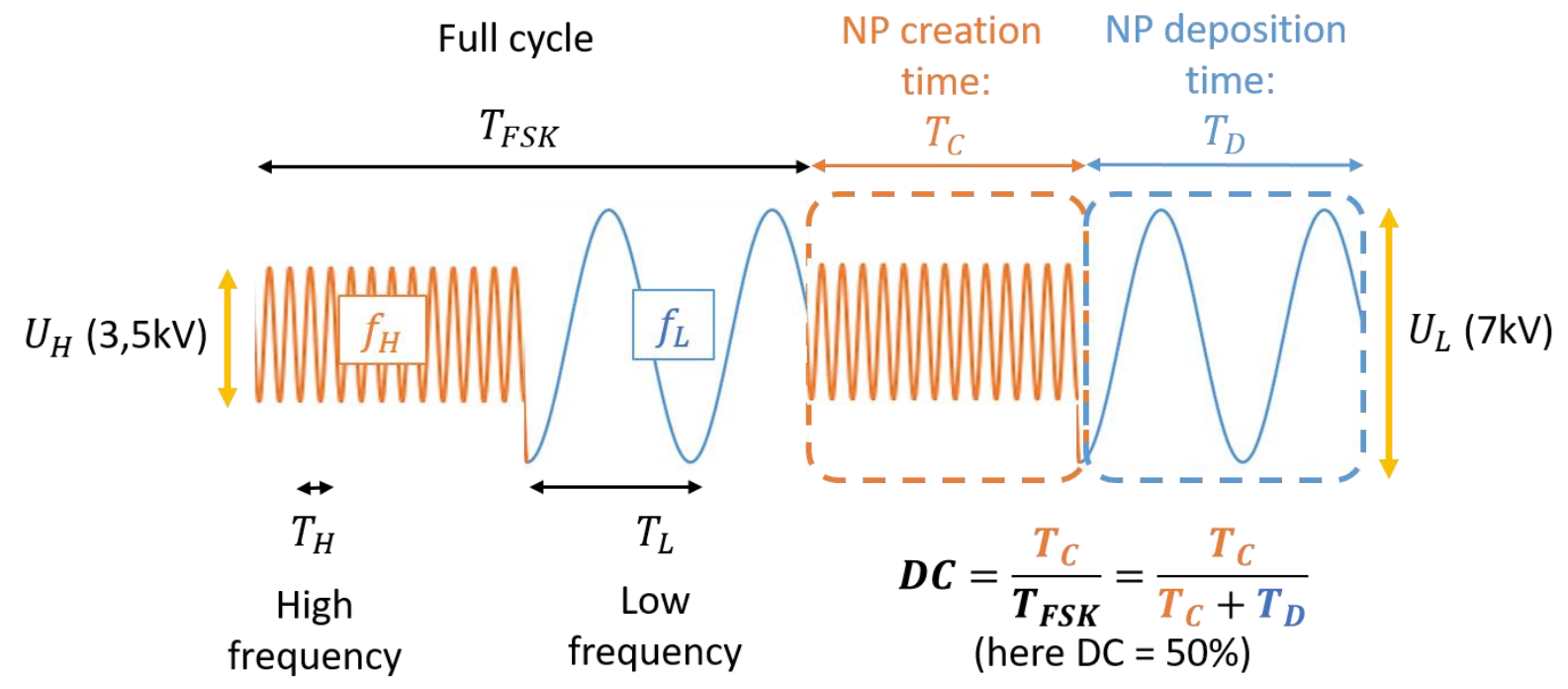

Figure 2: Typical example of FSK double modulation voltage used to drive the discharge. A high and low frequency voltage, respectively $U_{H}$ and $U_{L}$, are alternatively applied in order to 
control separately the time of NP creation (nanoparticle nucleation and growth and solvent polymerization mainly controlled by the high frequency plasma) and the time of NPs deposition (charged particles are driven toward the electrodes and deposited on the substrate by the low frequency voltage).

The values of the high and the low frequencies were chosen according to previous studies $[38,39]$. It was shown that the high frequency should be larger than $10 \mathrm{kHz}$ to ensure a thin film deposition from IP and the low frequency, lower than $1 \mathrm{kHz}$ to ensure an efficient transport of the NPs onto the surface as soon as they have a charge of constant polarity. On the other hand, due to the characteristics of the high-voltage transformer, the frequency values allowing to produce a voltage high enough to turn on the plasma lie between $0.5 \mathrm{kHz}$ and $20 \mathrm{kHz}$. Accordingly, the low frequency $\left(\mathrm{f}_{\mathrm{L}}\right)$ value was set at $0.8 \mathrm{kHz}$ while the high frequency $\left(\mathrm{f}_{\mathrm{H}}\right)$ is set at $20 \mathrm{kHz}$. In all cases, the amplitude of the high frequency voltage (peak-to-peak) is 2 times that of the low frequency value. Typically, the amplitude of the $20 \mathrm{kHz}$ and $800 \mathrm{~Hz}$ voltages are $7 \mathrm{kV}$ and $3.5 \mathrm{kV}$, respectively. This difference is due to the high voltage transformer characteristics. Depending on the experimental conditions, like the precursor concentration, the amplitude of these voltages are adjusted to maintain the discharges power close to 0.2 and 0.7 W. $\mathrm{cm}^{-2}$ for the high and the low frequency DBD respectively.

A large number of synthesis parameters can be considered, such as the nature of metal salt (type of metal, redox potential of metallic ion, counter ion etc.), the type of solvent (polarity, molecular weight, polymerization rate etc.) and the salt concentration but also the aerosol flow and dilution and all electrical parameters such as FSK frequency, DC or deposition time. To simplify the analysis, only four parameters were considered in this work: i) the concentration of gold atoms in the isopropanol (in w\%), ii) the duty cycle $(D C)$ and iii) the frequency rate $\left(f_{F S K}\right)$ of the voltage applied to the electrodes and iv) the position of the analyzed zone of the samples. Due to the lateral injection of the gas, this position is associated to a gas mean 
residence time of the reactive species in the plasma. As the nature of the deposited film might evolve with this time all samples are characterized on 3 different zones having a typical size of $2 \mathrm{~mm}$ and located along the flow direction. as shown in Erreur! Source du renvoi introuvable..(a). The totality of the synthesis parameters explored in this study is summarized in the table in Figure 3.(c).

(a)

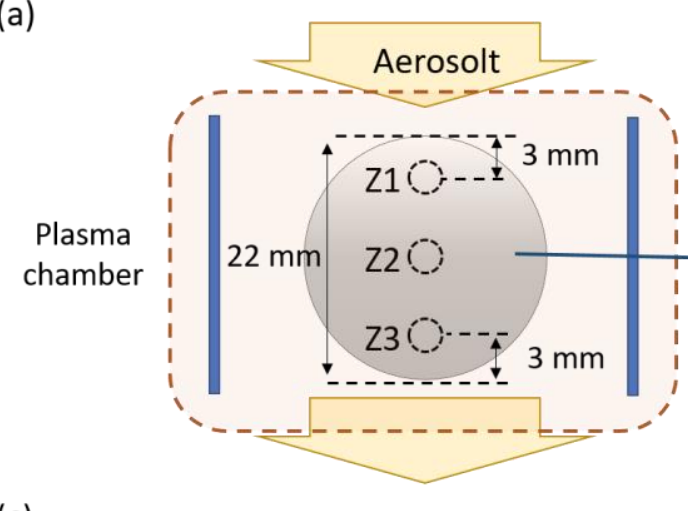

(b)

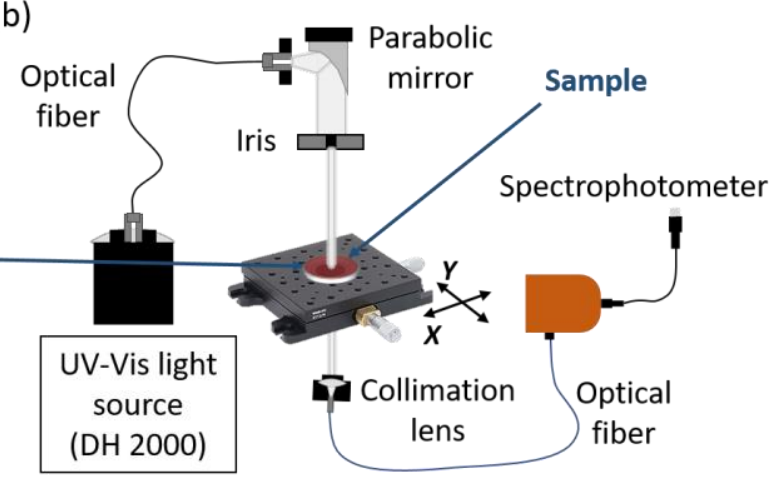

(c)

\begin{tabular}{|c|c|c|c|}
\hline Gold atoms weight percentage in the initial solution & \multicolumn{3}{|c|}{$0.015 \mathrm{w} \%-0.025 \mathrm{w} \%-0.05 \mathrm{w} \%$} \\
\hline Duty cycle: $D C$ & \multicolumn{3}{|c|}{$25 \%-50 \%-80 \%$} \\
(Ratio of high to low plasma frequency) & Zone 1: & Zone 2: & Zone 3: \\
\hline Analyzed area & $3 \mathrm{~mm}$ & $11 \mathrm{~mm}$ & $19 \mathrm{~mm}$ \\
Distance to the plasma entrance & $6 \mathrm{~ms}$ & $22 \mathrm{~ms}$ & $38 \mathrm{~ms}$ \\
Mean gas residence time & \multicolumn{3}{|c|}{$100 \mathrm{~Hz}-300 \mathrm{~Hz}$} \\
\hline FSK frequency (repetition rate): $\mathrm{f}_{\mathrm{FSK}}$ &
\end{tabular}

Figure 3: (a) Definition of the different zones studied on each sample along the flow direction (b) optical setup used to locally measure the absorption spectra on zones 1, 2 and 3. (c) Summary of the values of the different synthesis parameters that have been explored in this study.

The surface topology of the fabricated thin films was characterized by AFM (Model SMENA, NT-MDT) on the different zones depicted in Erreur ! Source du renvoi introuvable.. As the 
deposited films are homogeneous at the scale of hundreds of microns, AFM images of $1 \mu \mathrm{m}^{2}$ were recorded. This size was the most relevant to get information on both NPs dimension and spatial distribution. As the IP polymerization is low, AFM enables a direct observation of the nanoparticles and their spatial distribution which is not possible by using TEM for samples deposited on a glass substrate.

Absorption spectra from $400 \mathrm{~nm}$ to $900 \mathrm{~nm}$ was measured locally with a dedicated setup, schematized in Erreur ! Source du renvoi introuvable.(b). These measurements exhibit the plasmon resonance profile of the nanocomposites which: i) is a signature of gold NPs and hence give a direct confirmation of their formation ii) contain precious information regarding the nanoparticle size, morphology and spatial arrangement in the films and iii) can be combined with local AFM images for analysis and interpretation.

\section{RESULTS AND DISCUSSION}

\subsection{Effect of Au concentration in the solution used to produce the aerosol}

Gold concentration is a key parameter, as making a metal/polymer nanocomposite with a high concentration of metals NPs is still challenging. Erreur! Source du renvoi introuvable. shows the results obtained for 3 samples, $S_{1}, S_{2}$ and $S_{3}$ prepared in similar plasma conditions $\left(f_{F S K}=100 \mathrm{~Hz}, D C=25 \%\right)$ and for Au concentration of $0.015,0.025$ and 0.050 $\mathrm{w} \%$ respectively. The upper value is close to the limit of solubility of the gold salt in the IP at ambient temperature (higher concentration can eventually be obtained by heating up the IP around $60^{\circ} \mathrm{C}$ under stirring). 


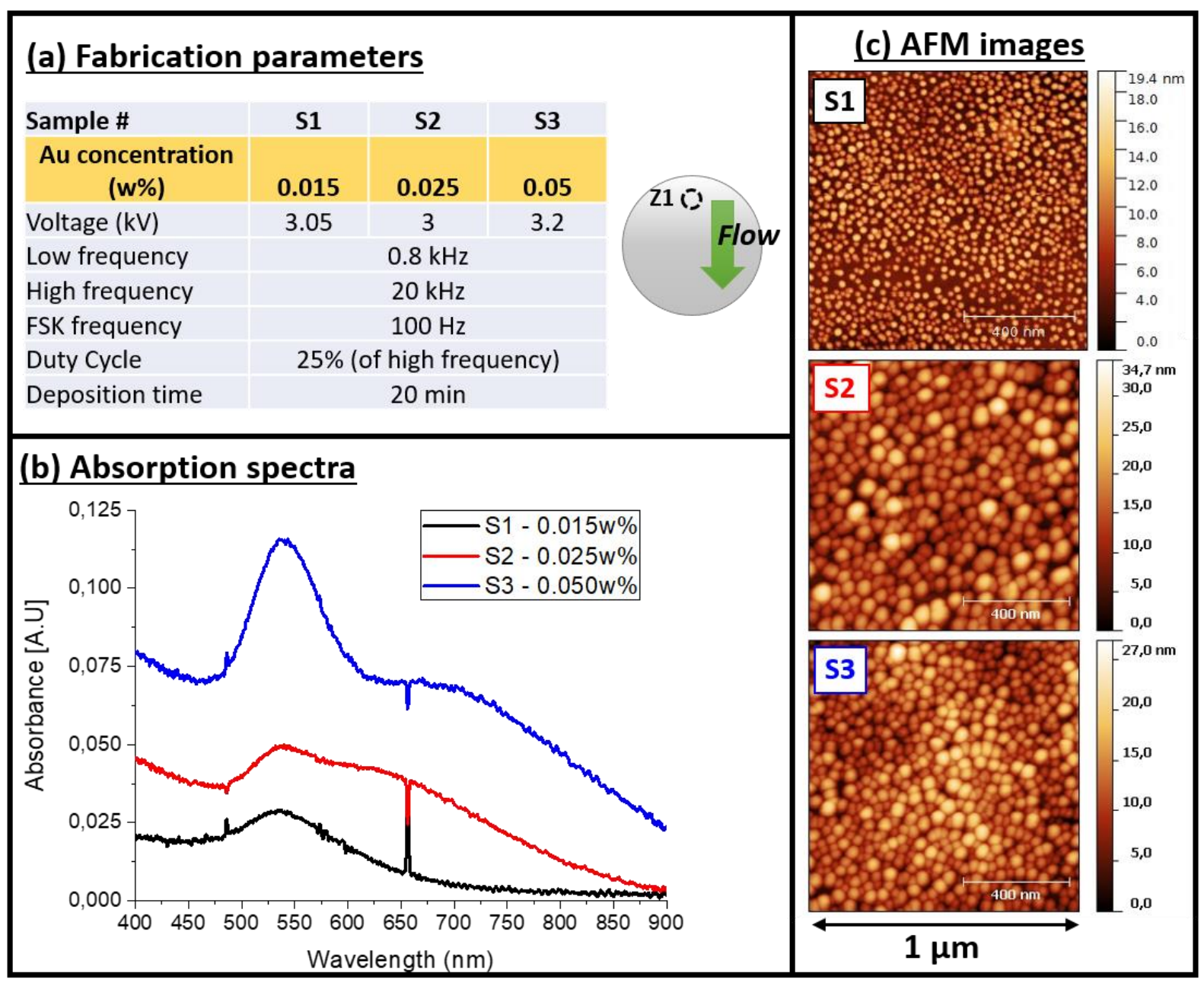

Figure 4: EFFECT OF AU CONCENTRATION (a) Summary table of fabrication parameters (b) Absorption spectra measured on zone 1 of samples prepared with different concentration. (c) Corresponding AFM images of $1 \mu^{2}$ size.

The results presented in Erreur ! Source du renvoi introuvable. are from zone 1 (Erreur ! Source du renvoi introuvable.). AFM images, given in Erreur! Source du renvoi introuvable.. (c). confirm the formation of dense films of non-aggregated NPs deposited on the glass substrate surface for the 3 salt concentrations. In the plasma condition used, the polymerization of the IP seems to be to too low to form a continuous matrix that would surround the NPs. These observations are substantiated by the absorption spectra, which clearly show the plasmonic response of gold with a resonance centered around $540 \mathrm{~nm}[46,52]$. The spectrum of $\mathrm{S}_{1}$, which is the sample at the lowest concentration corresponds to a typical spectrum of isolated 
nanoparticles with only one resonance peak. Accordingly, the AFM image of $\mathrm{S}_{1}$ shows that the surface is covered by a layer of almost non-touching nanoparticles. For the higher gold concentrations $\left(\mathrm{S}_{2}\right.$ and $\left.\mathrm{S}_{3}\right)$, the NP size increases and the assemblies are much denser in agreement with a larger nucleation and a higher growth rate of the NPs, which seems logical as the amount of available precursor also increases. However, the largest NPs size is observed for the intermediate concentration while the NP density in the film seems to increase more for $\mathrm{S}_{3}$. This can be explained by a variation of the equilibrium between nucleation and growth rate: the largest concentration induces a larger nucleation more than a larger growth rate. The optical spectra of the different samples are usual for gold NPs films. First, regarding the plasmon resonance profiles, we see the usual plasmonic peak around $540 \mathrm{~nm}$ [46]. A broad absorption is also observed at larger wavelengths for S2 and S3. It is known that as the inter-particle distance shortens, a near-field coupling emerges. This coupling leads to a collective mode characterized by a second plasmon resonance, red-shifted compared to the main resonance of gold $[45,48]$. This phenomenon is observed on the absorption spectra of $S_{2}$ and $S_{3}$ where a shoulder overlaps with the main peaks appearing respectively around $640 \mathrm{~nm}$ and $680 \mathrm{~nm}$. The position of this collective mode being more red-shifted as the inter-particle distance decreases, the $\mathrm{S}_{3}$ larger shift is in agreement with a denser layer. Secondly, regarding the amplitude of the absorption, we observe a clear increase of the absorption that is well correlated with the increase of the gold salt concentration. This latter result, along with the densification of the films observed on the AFM images tends to indicate that the ability of the plasma to act as "reducing agent" is not a limiting factor to trigger the nanoparticles nucleation and growth, even at high gold concentrations.

\subsection{Effect of Duty Cycle (DC)}


Figure 5 shows the results obtained for 3 samples prepared with an intermediary $\mathrm{Au}$ concentration of $0.025 \mathrm{w} \%$ and similar plasma conditions $\left(f_{F S K}=100 \mathrm{~Hz}\right)$ apart for the DC that is set to $25 \%, 50 \%$ and $80 \%$ for samples S2, S4 and S5 respectively. The corresponding NP creation times, $T_{c}$, and NP deposition times, $T_{D}$, are given in the table of Figure 5.(a). Here again, results of zone 1 only are presented.

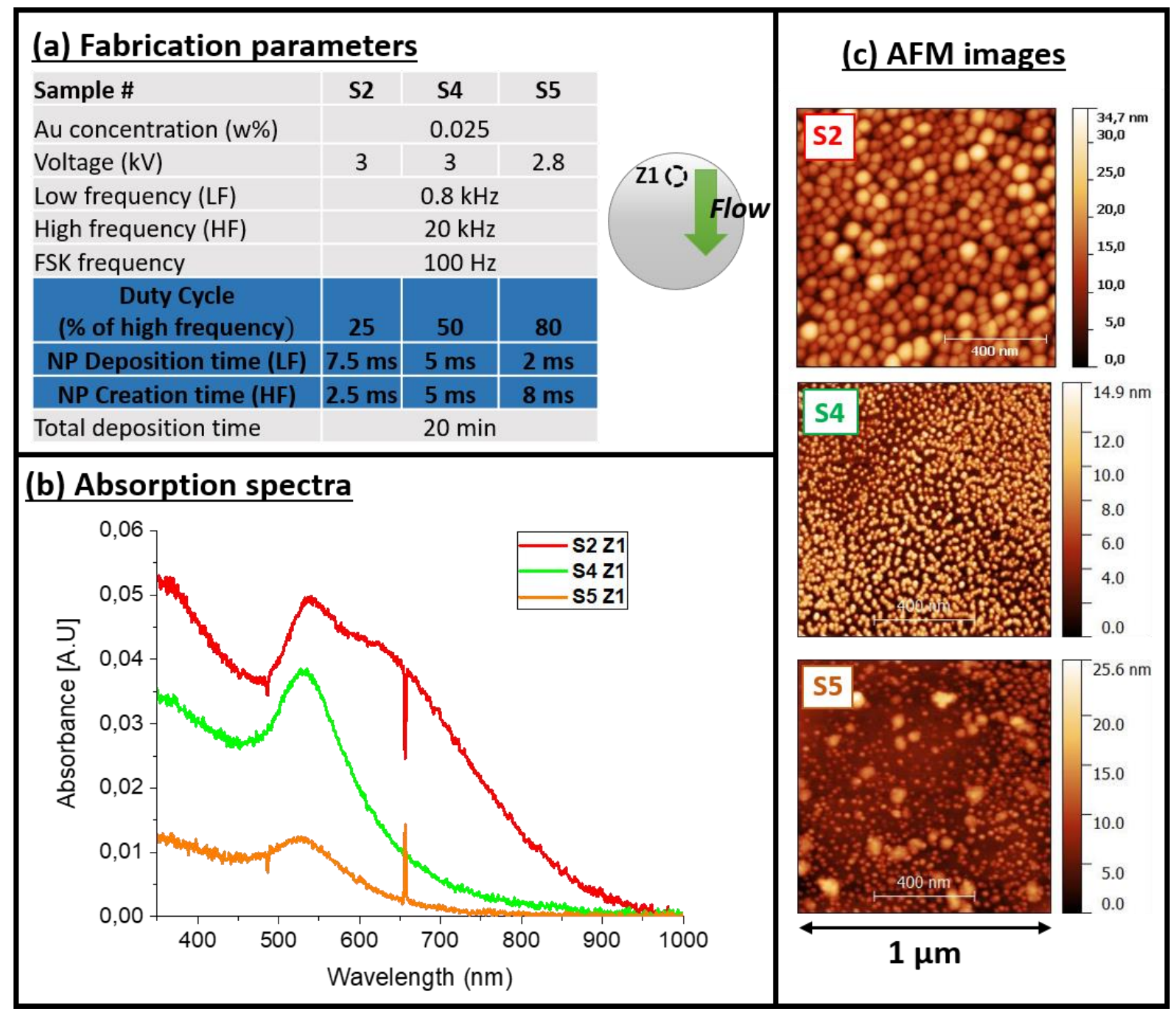

Figure 5: EFFECT OF THE DC (a) Summary table of fabrication parameters and evolution of the NP creation and deposition time depending on the DC. (b) Absorption spectra measured on zone 1 of samples prepared with different DC. (c) Corresponding AFM images of $1 \mu \mathrm{m} 2$ size. 
Compared to the previous results (represented here by $\mathrm{S}_{2}$ ), AFM images in Figure 5.(c). shows that increasing the DC, which corresponds to an increase of $T_{C}$ and thus a decrease of $T_{D}$, leads first to a clear decrease of the size of the NPs that are deposited with the observation of large aggregates for the largest DC. These data are further confirmed by UV-Vis spectroscopy, which shows that the increase of the DC induces a single resonance, in agreement with a lower nanoparticle coverage whereas a collective mode arises as the NPs get closer. This confirms that when using an FSK modulation approach: i) the period when high frequency is applied corresponds to the nanoparticle and polymer formation (as the plasma is at the highest energy and ionization level available) and ii) the period when the low frequency is applied is associated with NP transport toward the electrodes, as they can more easily follow the low frequency alternating electric field than the high frequency one (NPs are too heavy to follow the electric field at high frequency). When the DC increases, the NPs creation time also increases, which would logically lead to larger NPs and NPs aggregates in $\mathrm{S}_{4}$ and $\mathrm{S}_{5}$ compared to $\mathrm{S}_{2}$, but the contrary is observed. This might be due to the fact that as the NP size increases, they might not have enough time to be transported to the surface. Indeed, the transport of the NPs, toward the electrodes is mainly imposed by the Lorentz force. In this case, if we neglect the other forces that can affect the NPs trajectory in the vertical direction (mainly ion drag and thermophoresis) and that are negligible compared to the Lorentz force [53], the vertical component of the acceleration of the NPs is given by

$$
a_{z}=\frac{q}{m} E_{z}=\frac{3 \sigma}{\rho R} E_{z}
$$

where $\sigma$ is the surface loading, $\rho$ is the NP density, $R$ the NP radius, $E_{L, z}$ the amplitude of the low frequency electric field between the electrodes.

Consequently, as the size of the created NPs increases, the deflection of the NP trajectory induced by the low frequency voltage to insure their transport toward the substrate decreases. All the more so as, considering for example a DC of $80 \%$, there is approximately only one full 
alternation of the low frequency during $\mathrm{T}_{L}$, which also tend to limit the NPs transport, especially at the beginning of the deposition (Z1). This was previously observed for $\mathrm{TiO}_{2} \mathrm{NPs}$. It was shown that frequencies between 1 and $3 \mathrm{kHz}$ acts as a filter in size for NPs as higher is the frequency and higher is the size of the NPs, lower is the deflection of the NPs trajectory due to the voltage. Indeed, the gas flow transports the NPs parallel to the substrate, while the electrostatic forces transport them onto the substrate. Therefore, the deflection increases the density of NPs on the NC. The ratio between the densities of $\mathrm{Au}$ and $\mathrm{TiO}_{2}$ is approximately of $5\left(\rho_{A u}=19,3 \mathrm{~g} / \mathrm{cm}^{3}\right.$ and $\left.\rho_{\mathrm{TiO}_{2}}=4,25 \mathrm{~g} / \mathrm{cm}^{3}\right)$ which explains why $1 \mathrm{kHz}$ could be too high to efficiently transport Au NPs if their size is too large. In addition, it should be pointed out that the discharge is filamentary. For this reason, it only statistically fills the entire gas gap volume and accordingly, it takes more than one cycle to efficiently charge NPs, at least at the plasma entrance. For this reasons, it is interesting to study how the NPs density evolves along the gas flow direction.

\subsection{Evolution of the coating along the gas flow direction: effect of FSK frequency}

Figure 6 shows the evolution of both absorption spectra (see Figure 6.(b).) and AFM images (see Figure 6.(c).) of sample $\mathrm{S}_{4}(\mathrm{DC}=50 \%$ and FSK frequency of $100 \mathrm{~Hz}$ ) from zones 1 to 3 . The AFM images show a progressive increase of the NP size from to zone 1 to zone 3. This confirms the previous explanation as in zone 1, only the smallest NPs are deposited, larger NPs takes a longer time to reach the surface, allowing their deposition in zone 2 or 3 . In these latter zones, small NPs are also observed. They probably began to grow further away from the plasma entrance. 


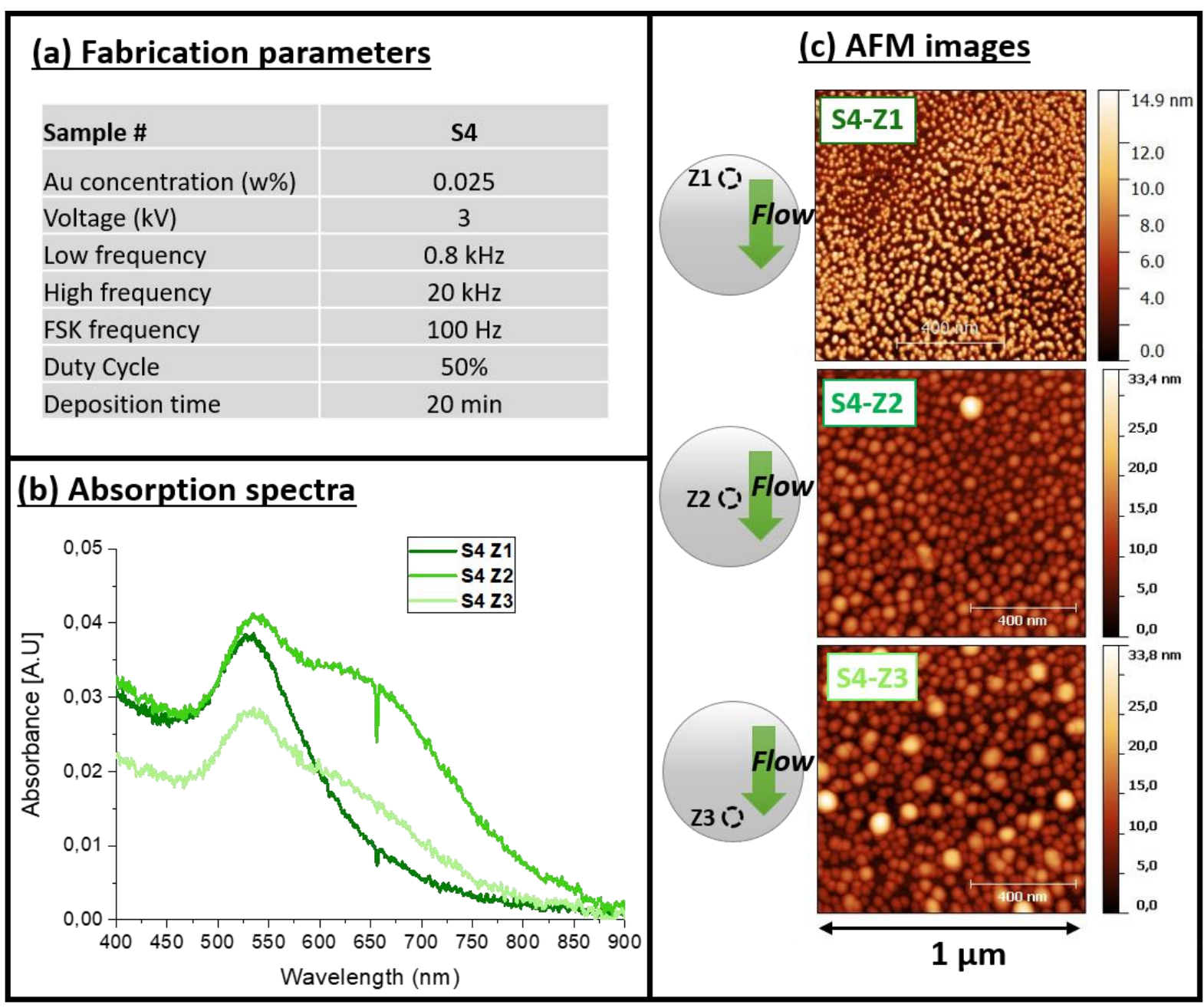

Figure 6: EFFECT OF THE POSITION - case 1 (a) Summary table of fabrication parameters (b) Absorption spectra measured on zones 1, 2 and 3. (c) Corresponding AFM 1 $\mu m^{2}$ images.

The UV-VIS absorption spectra are in agreement with the spatial distribution of the NPs observed. Indeed, a decrease of the absorbance magnitude is observed in zone 3 (as compared to zone 2), due to a slightly lower density of NPs on the surface. This phenomenon is likely due to the salt consumption: the Au precursor concentration progressively decreases as NPs are formed in situ, therefore limiting the NPs formation at the end of the plasma chamber.

As the evolution of the NP size across the sample might be a problem for manufacturing nanocomposites with tailored properties, one should question on how controlling NP growth all along the plasma to get a monodisperse size distribution. A straightforward way to solve this 
issue is to shorten the period in which the nanoparticle are both created $\left(T_{C}\right)$ and deposited $\left(T_{D}\right)$, which is determined by the total FSK period $\left(T_{F S K}=T_{C}+T_{D}\right)$. Figure 7 presents the observations made in the 3 zones of sample $\mathrm{S}_{6}$, prepared with a higher FSK frequency than sample $\mathrm{S}_{4}\left(f_{F S K}\right.$ going from $100 \mathrm{~Hz}$ for $\mathrm{S}_{4}$ to $300 \mathrm{~Hz}$ for $\mathrm{S}_{6}$ i.e. $T_{F S K}$ going from $10 \mathrm{~ms}$ for $\mathrm{S}_{4}$ to $3,3 \mathrm{~ms}$ for $\mathrm{S}_{6}$ ). The AFM images in Figure 7.(c). clearly show that the NPs deposited are much more monodisperse in size. They keep an almost identical size across zones 1 to 3 .

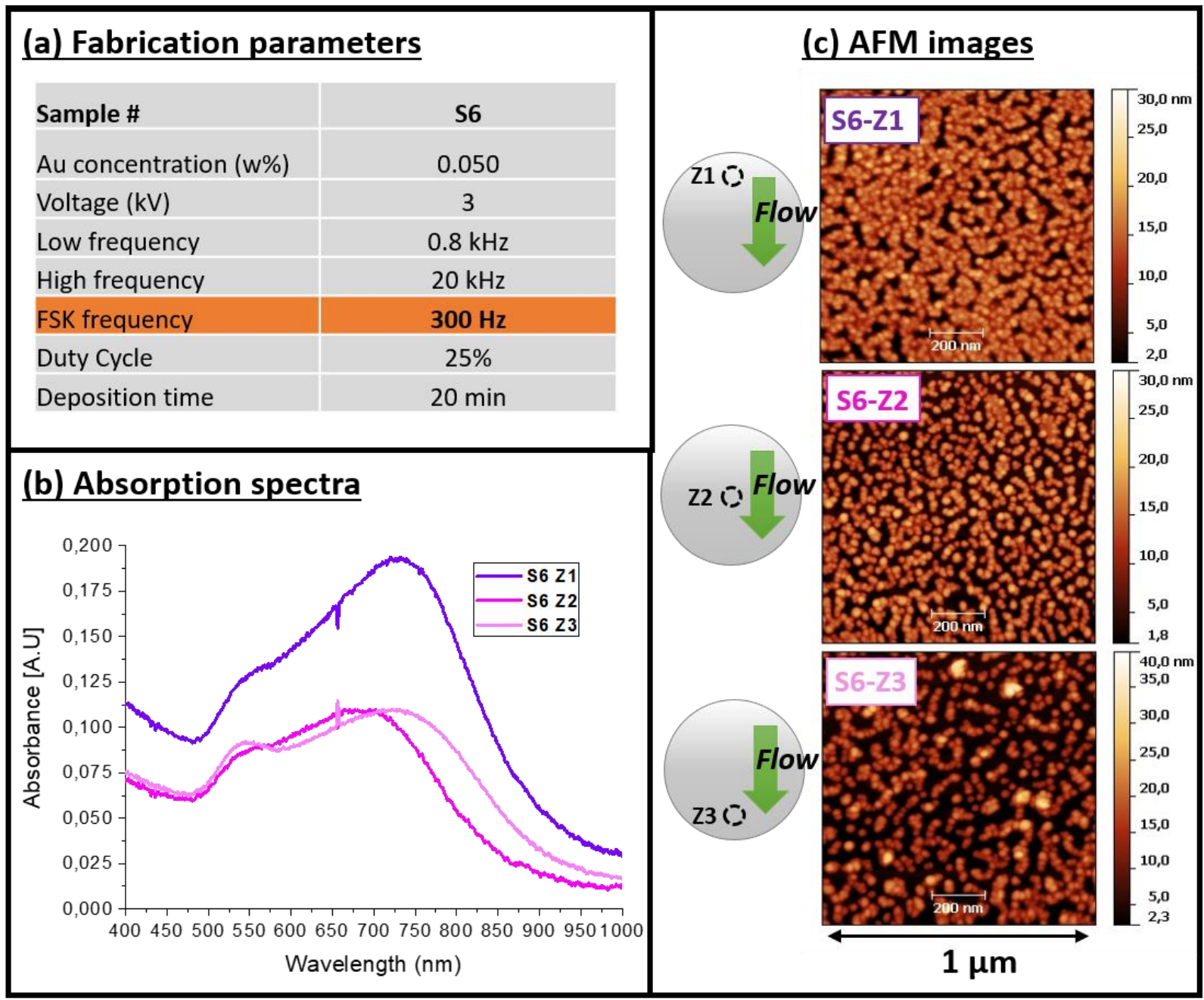

Figure 7: EFFECT OF THE POSITION - case 2 (a) Summary table of fabrication parameters (b) Absorption spectra measured on samples prepared in zones 1, 2 and 3 (see Erreur! Source du renvoi introuvable.). (c) Corresponding $1 \mu^{2}$ AFM images).

The optical spectra show that collective modes are dominating the absorption, with strong absorption peak centered between 700 and $750 \mathrm{~nm}$. This observation is in agreement with the 
AFM images, which show that the NPs are in very close proximity on all zones, even when the coverage decreases, as they tend to form small chains, therefore maintaining a strong near-field coupling in all cases. This result is of paramount importance, as it shows that using a wide range of fabrication parameters enables to synthesize plasmonic absorbers with controlled optical properties with resonance peaks ranging from $540 \mathrm{~nm}$ to $750 \mathrm{~nm}$.

That said, it is evident that the NPs surface density decreases along the flow direction (zones 1 to 3). As aforementioned, this decrease in density might be due to i) the consumption of the $\mathrm{Au}$ salt along the discharge, but this explanation is questionable as the concentration was increased and ii) the fact that larger NPs are still formed, and thus are consuming the Au precursor, but are not deposited because of the filtering applied by increasing the FSK frequency.

In practice, the drawback which is the inhomogeneity of the NP density across the deposition area could be easily solved by using a different deposition protocol based on a moving substrate. Indeed, it is possible to obtain a homogeneous coverage of the whole substrate by adjusting the substrate speed.

\section{CONCLUSIONS}

This study presents a new method to synthetize gold/polymer nanocomposite thin films avoiding NPs aggregates. It shows, for the first time, that gold nanoparticles can be in situ synthesized inside a cold plasma at atmospheric pressure, from injected metal salts suspension in the form of an aerosol, and co-deposited with a polymer matrix to fabricate a NC film. The method uses the ability of plasma ionized species to reduce a metallic salt and the energetic species to polymerize a solvent to produce thin films by plasma enhanced chemical vapor polymerization (PECVD). The power of a $20 \mathrm{kHz}$ DBD is large enough for this process.

In this one-step process, gold NPs are created and embedded in a polymer matrix, by the use of FSK modulations of a linear DBD plasma in argon in which is pulverized a metal salt solution. This method has proven to be effective and reproducible. Metal salt initial 
concentration and FSK parameters lead to different sizes and spatial distributions of the deposited NPs. FSK frequency is a key to get uniform coatings with a rather thin NPs size distribution on $2 \mathrm{~cm}$-long samples and $44 \mathrm{~ms}$ precursors residence time in the plasma.

The studied experimental parameters, that are gold concentration, FSK parameters and position along the gas flow allow to change the size of the gold NPs, their concentration and level of plasmonic coupling allowing the synthesis of plasmonic absorbers with controlled optical properties, exhibiting resonance peaks ranging from $540 \mathrm{~nm}$ to $750 \mathrm{~nm}$.

Upscaling should be straightforward as the linear DBD configuration is commonly used for online large-scale surface treatments. As this method is based on the reduction of metal ions, it is possible to extrapolate this method to other metal salts, such as silver or even iron, opening the way to the synthesis of a wide range of nanocomposite materials with diverse properties. A deeper understanding of the interaction of the salt and the energetic species of the plasma will be necessary to optimize this promising process. The solvent polymerization ability is certainly a key parameter to control the concentration of NPs and should be studied. However, this study demonstrates the possibility to obtain a certain degree of control on the NPs and the NC morphology, as well as to improve safety (by avoiding the direct manipulation of the NPs), to reduce the preparation time and cost (one step continuous deposition on moving substrate), and to minimize the probability of oxidation of NPs in NCs.

\section{ACKNOWLEDGMENTS}

?????????????????????????????????????????????????

\section{REFERENCES}

[1] Dreaden E C, Austin L A, MacKey M A and El-Sayed M A 2012 Size matters: Gold nanoparticles in targeted cancer drug delivery Ther. Deliv. 
[2] Rahman Z U, Zhang T, Feng Y, Ye W and Wang D 2017 Preparation of Gold Shells on Hollow Mesoporous Silica Nanospheres and Application to PhotothermalChemotherapy ChemistrySelect

[3] Lee T, Bang D, Chang Y W, Choi Y, Park K Y, Oh A, Han S, Kim S H, Lee K, Suh J S, Huh Y M and Haam S 2016 Cancer theranosis using mono-disperse, mesoporous gold nanoparticles obtained via a robust, high-yield synthetic methodology $R S C A d v$.

[4] Yeh Y C, Creran B and Rotello V M 2012 Gold nanoparticles: Preparation, properties, and applications in bionanotechnology Nanoscale

[5] Stratakis E and Kymakis E 2013 Nanoparticle-based plasmonic organic photovoltaic devices Mater. Today 16 133-46

[6] Wu J L, Chen F C, Hsiao Y S, Chien F C, Chen P, Kuo C H, Huang M H and Hsu C S 2011 Surface plasmonic effects of metallic nanoparticles on the performance of polymer bulk heterojunction solar cells ACS Nano 5 959-67

[7] Narang P, Sundararaman R and Atwater H A 2016 Plasmonic hot carrier dynamics in solid-state and chemical systems for energy conversion Nanophotonics

[8] Atwater H A and Polman A 2010 Plasmonics for improved photovoltaic devices. Nat. Mater. 9 205-13

[9] Grzelczak M, Pérez-Juste J, Mulvaney P and Liz-Marzán L M 2008 Shape control in gold nanoparticle synthesis Chem. Soc. Rev. 37 1783-91

[10] Thanh N T K, Maclean N and Mahiddine S 2014 Mechanisms of nucleation and growth of nanoparticles in solution Chem. Rev. 114 7610-30

[11] Lukaszkowicz K 2011 Review of Nanocomposite Thin Films and Coatings Deposited by PVD and CVD Technology Nanomaterials

[12] Biswas A, Bayer I S, Biris A S, Wang T, Dervishi E and Faupel F 2012 Advances in top-down and bottom-up surface nanofabrication: Techniques, applications \& future prospects $A d v$. Colloid Interface Sci. 
[13] Faupel F, Zaporojtchenko V, Greve H, Schürmann U, Chakravadhanula V S K, Hanisch C, Kulkarni A, Gerber A, Quandt E and Podschun R 2007 Deposition of nanocomposites by plasmas Contributions to Plasma Physics

[14] Chen Y 2015 Nanofabrication by electron beam lithography and its applications: A review Microelectron. Eng.

[15] Baglin J E E 2012 Ion beam nanoscale fabrication and lithography - A review Applied Surface Science

[16] Pimpin A and Srituravanich W 2012 Reviews on micro- and nanolithography techniques and their applications Eng. $J$.

[17] Wu D, S. Rajput N and Luo X 2016 Nanoimprint Lithography - the Past, the Present and the Future Curr. Nanosci.

[18] Wang W, Ramezani M, Väkeväinen A I, Törmä P, Rivas J G and Odom T W 2018 The rich photonic world of plasmonic nanoparticle arrays Mater. Today

[19] Humphrey A D and Barnes W L 2014 Plasmonic surface lattice resonances on arrays of different lattice symmetry Phys. Rev. B - Condens. Matter Mater. Phys.

[20] Hanemann T and Szabó D V 2010 Polymer-nanoparticle composites: From synthesis to modern applications Materials (Basel).

[21] Rane A V, Kanny K, Abitha V K and Thomas S 2018 Methods for Synthesis of Nanoparticles and Fabrication of Nanocomposites Synthesis of Inorganic Nanomaterials

[22] Sperling R A and Parak W J 2010 Surface modification, functionalization and bioconjugation of colloidal Inorganic nanoparticles Philos. Trans. R. Soc. A Math. Phys. Eng. Sci. 368 1333-83

[23] Mout R, Moyano D F, Rana S and Rotello V M 2012 Surface functionalization of nanoparticles for nanomedicine Chem. Soc. Rev.

[24] Neouze M A and Schubert U 2008 Surface modification and functionalization of metal and metal oxide nanoparticles by organic ligands Monatshefte fur Chemie 
[25] SETHI A, Rafiee M, Chandra S, Ahmed H and McCormack S 2019 A unified methodology for fabrication and quantification of gold nanorods, gold core silver shell nanocuboids and their polymer nanocomposites Langmuir acs.langmuir.9b01481

[26] Porel S, Venkatram N, Rao D N and Radhakrishnan T P 2007 In situ synthesis of metal nanoparticles in polymer matrix and their optical limiting applications. J. Nanosci. Nanotechnol. 7 1887-92

[27] Nadal E, Barros N, Peres L, Goetz V, Respaud M, Soulantica K and Kachachi H 2020 In situ synthesis of gold nanoparticles in polymer films under concentrated sunlight: control of nanoparticle size and shape with solar flux React. Chem. Eng. 29-31

[28] Nadal E, Barros N, Glénat H and Kachakachi H 2018 Optical Properties of Complex Plasmonic Materials Studied with Extended Effective Medium Theories Combined with Rigorous Coupled Wave Analysis Materials (Basel). 11351

[29] Nadal E, Barros N, Glénat H, Laverdant J, Schmool D S and Kachkachi H 2017 Plasmon-enhanced diffraction in nanoparticle gratings fabricated by in situ photoreduction of gold chloride doped polymer thin films by laser interference patterning $J$. Mater. Chem. C 5 3553-60

[30] Pucci A, Bernabò M, Elvati P, Meza L I, Galembeck F, de Paula Leite C A, Tirelli N and Ruggeri G 2006 Photoinduced formation of gold nanoparticles into vinyl alcohol based polymers J. Mater. Chem. $161058-66$

[31] Diao Y, Shaw L, Bao Z and Mannsfeld S C B 2014 Morphology control strategies for solution-processed organic semiconductor thin films Energy Environ. Sci. 7 2145-59

[32] Grosso D, Boissière C and Faustini M 2015 Thin Film Deposition Techniques The SolGel Handbook

[33] Li J G, Büchel R, Isobe M, Mori T and Ishigaki T 2009 Cobalt-doped TiO2 nanocrystallites: Radio-frequency thermal plasma processing, phase structure, and magnetic properties J. Phys. Chem. C 
[34] Mariotti D and Sankaran R M 2010 Microplasmas for nanomaterials synthesis J. Phys. D. Appl. Phys. 43

[35] Bruggeman P J, Kushner M J, Locke B R, Gardeniers J G E, Graham W G, Graves D B, Hofman-Caris R C H M, Maric D, Reid J P, Ceriani E, Fernandez Rivas D, Foster J E, Garrick S C, Gorbanev Y, Hamaguchi S, Iza F, Jablonowski H, Klimova E, Kolb J, Krcma F, Lukes P, MacHala Z, Marinov I, Mariotti D, Mededovic Thagard S, Minakata D, Neyts E C, Pawlat J, Petrovic Z L, Pflieger R, Reuter S, Schram D C, Schröter S, Shiraiwa M, Tarabová B, Tsai P A, Verlet J R R, Von Woedtke T, Wilson K R, Yasui K and Zvereva G 2016 Plasma-liquid interactions: A review and roadmap Plasma Sources Sci. Technol.

[36] Profili J, Levasseur O, Blaisot J B, Koronai A, Stafford L and Gherardi N 2016 Nebulization of Nanocolloidal Suspensions for the Growth of Nanocomposite Coatings in Dielectric Barrier Discharges Plasma Process. Polym.

[37] Fanelli F, Mastrangelo A M and Fracassi F 2014 Aerosol-assisted atmospheric cold plasma deposition and characterization of superhydrophobic organic-inorganic nanocomposite thin films Langmuir

[38] Brunet P, Rincón R, Matouk Z, Chaker M and Massines F 2018 Tailored Waveform of Dielectric Barrier Discharge to Control Composite Thin Film Morphology Langmuir 34 $1865-72$

[39] Brunet P, Rincón R, Martinez J M, Matouk Z, Fanelli F, Chaker M and Massines F 2017 Control of composite thin film made in an Ar/isopropanol/TiO2 nanoparticles dielectric barrier discharge by the excitation frequency Plasma Process. Polym.

[40] Vallade J, Bazinette R, Gaudy L and Massines F 2014 Effect of glow DBD modulation on gas and thin film chemical composition: Case of Ar/SiH4/NH3 mixture J. Phys. D. Appl. Phys.

[41] Fanelli F and Fracassi F 2014 Aerosol-assisted atmospheric pressure cold plasma 
deposition of organic-inorganic nanocomposite coatings Plasma Chem. Plasma Process.

[42] Profili J, Levasseur O, Naudé N, Chaneac C, Stafford L and Gherardi N 2016 Influence of the voltage waveform during nanocomposite layer deposition by aerosol-assisted atmospheric pressure Townsend discharge J. Appl. Phys.

[43] Milaniak N, Laroche G and Massines F 2020 Atmospheric-pressure plasma-enhanced chemical vapor deposition of nanocomposite thin films from ethyl lactate and silica nanoparticles Plasma Process. Polym.

[44] Massines F, Sarra-Bournet C, Fanelli F, Naudé N and Gherardi N 2012 Atmospheric pressure low temperature direct plasma technology: Status and challenges for thin film deposition Plasma Process. Polym. 9 1041-73

[45] Trügler A 2011 Optical properties of metallic nanoparticles Dissertation

[46] Noguez C 2007 Surface Plasmons on Metal Nanoparticles: The Influence of Shape and Physical Environment J. Phys. Chem. C $1113806-19$

[47] Wormeester H and Oates T W H 2013 Thin films of nanostructured noble metals

[48] Ghosh S K and Pal T 2007 Interparticle coupling effect on the surface plasmon resonance of gold nanoparticles: from theory to applications. Chem. Rev. 107 4797-862

[49] Daruich De Souza C, Ribeiro Nogueira B and Rostelato M E C M 2019 Review of the methodologies used in the synthesis gold nanoparticles by chemical reduction J. Alloys Compd. $798714-40$

[50] Xia Y, Xiong Y, Lim B and Skrabalak S E 2009 Shape-Controlled Synthesis of Metal Nanocrystals: Simple Chemistry Meets Complex Physics? Angew. Chemie Int. Ed. 48 $60-103$

[51] Thanh N T K, Maclean N and Mahiddine S 2014 Mechanisms of Nucleation and Growth of Nanoparticles in Solution Chem. Rev. 114 7610-30

[52] Haiss W, Thanh N T K, Aveyard J and Fernig D G 2007 Determination of size and concentration of gold nanoparticles from UV-Vis spectra Anal. Chem. 79 4215-21 
[53] Jidenko N, Jimenez C, Massines F and Borra J P 2007 Nano-particle size-dependent charging and electro-deposition in dielectric barrier discharges at atmospheric pressure for thin SiOx film deposition J. Phys. D. Appl. Phys. 